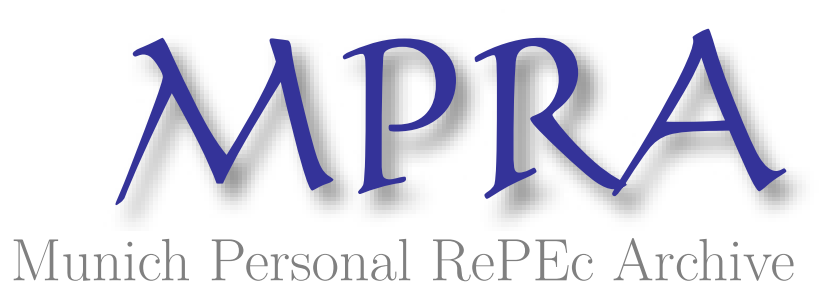

\title{
Primary-input intensities under alternative measures of rent content
}

Londero, Elio

September 2000

Online at https://mpra.ub.uni-muenchen.de/100633/

MPRA Paper No. 100633, posted 01 Jun 2020 05:03 UTC 


\title{
PRIMARY-INPUT INTENSITIES UNDER ALTERNATIVE MEASURES OF RENT CONTENT
}

\author{
by Elio Londero *
}

September, 2000

\begin{abstract}
Different methods for measuring rent (natural-resource) content have been proposed in studies of the primary-input content of trade. In this paper these methods are applied to obtain different industry-level estimates of the primary-input contents and the primary-input intensities of Argentina's exports of manufactures. The paper then explores the extent to which the choice of method affects these results, as well as the classification and ranking of activities according to primary-input intensities, and Heckscher-Ohlin tests.
\end{abstract}

\section{J. E. L. Classification No: C67, F11, F14}

Keywords: measuring rent content, factor intensity, Heckscher-Ohlin

* Inter-American Development Bank. Opinions expressed in this paper are those of the author and are not intended to represent the views of the Bank. A shorter version excluding some figures and tables was accepted for publication in the Journal of International Trade and Economic Development 10(4), 2001, https://doi.org/10.1080/09638190110073796. Comments by Simón Teitel and two anonymous referees are gratefully acknowledged, as is valuable help from Carola Alvarez, Pablo Londero, Mirta Taito, and Glenn Westley. The author remains solely responsible for the result. 


\section{Introduction}

In international trade theory, the Heckscher-Ohlin (H-O) theorem shows that primaryinput ("factor") endowments would be crucial determinants of the composition of primary-input "services" embodied in its trade flows. Many empirical studies have been conducted to test $\mathrm{H}-\mathrm{O}$ propositions by studying the relationship between primary-input endowments and the primary-input content of trade in goods. ${ }^{1}$

In two pioneering articles, Leontief $(1953,1956)$ analyzed the labor and capital content of United States foreign trade. He acknowledged the important role of natural resources in explaining the commodity composition of trade and some of the primaryinput-content results, pointing to the lack of data for the failure to incorporate them to the study. Vanek (1963) called again attention to natural resource endowments, and consequently to the rent content of industry output. He proposed a method for measuring "natural resource content" and focused his analysis in the role of natural resources in explaining US foreign trade. A significant part of the literature that followed was based on estimating the total primary-input content of trade using input-output (I-O) techniques.

Measuring the primary input content of trade using I-O tables requires a set of measures of direct primary-input use that can be translated into, or associated with entries in the I-O table. The problem is that I-O tables are based on data for current inputs and outputs, and such data does not separately impute rent and reproducible-capital-use costs. Rather, rents and reproducible-capital-use costs are lumped together in a residual category called the gross operating surplus. Thus, the use of I-O techniques requires an indirect measure of the share of rents in total value of production, and several alternatives have been proposed to that effect.

Vanek (1963) proposed using the "value of resource products" consumed as an indicator of the direct rent requirements. He defined resource products as "all commodities whose productive process makes direct use of natural resources, and for which values of output are currently recorded. Thus wheat grain is a resource product,

\footnotetext{
${ }^{1}$ Deardorff (1984) and Leamer and Levinsohn (1994) review empirical studies of the H-O model.
} 
while wheat flour is not, since it does not use land as a direct input" (p. 10). Total rent content would be estimated by the value of resource products required directly and indirectly to produce one unit of output, ${ }^{2}$ thus assuming that resource products are exclusively made of natural resources, and losing the information on current inputs into resource-product activities.

Another possibility would be to assume equal rent coefficients for all resourceproduct activities. This method was used by Postner (1975), who assumed that "the direct natural resource factor coefficients are positive and equal for all natural resource product industries" (p. 11). ${ }^{3}$ It preserves the proportionality with the total requirements of natural resource products, and has the advantages of taking into account differences in primaryinput content originating in the differences in the cost structures of the resource products, and of netting out the value of the imported inputs used in the production of resource products.

An alternative method, proposed by Londero (1998), is based on using the total primary-input content of the activity's output by using the gross operating surplus of the resource-product activity (GOSRPA) as a proxy for the direct rent content. ${ }^{4}$ This method and Postner's share over Vanek's method the advantage of making full use of the information provided by the cost structure of resource products.

A detailed formal comparison among these three methods, and a comparison of each method with the theoretically desirable measure, was conducted by Londero (1999) using the primary-input content of value of production -- the so-called "flow method" (Lary, 1968; and Balassa, 1979). This article shows algebraically how alternative measures of rent content affect primary-input contents and primary-input ratios (e.g,

\footnotetext{
${ }^{2}$ Vanek (1963) used an equivalent approach to calculate the resource-product content of U.S. trade. Naya (1967) used Vanek's approach to analyze the resource-product content of U.S. and Japanese trade. More recently, it was used by Ramazami and Maskus (1992), Maskus et al. (1994), and Engelbrecht (1996).

${ }^{3}$ Strictly speaking, Postner (1975, p. 11) assumed constant "physical" coefficients.

${ }^{4}$ For applications of this method see Londero and Teitel (1996); Londero, Teitel et al. (1998); and Moreira and Najberg (2000).
} 
capital to labor) establishing that in many cases it may be known without resorting to the data whether an activity's primary-input ratio calculated according to one method is higher or lower than the same ratio, for the same activity, but calculated according to another method. However, these results do not indicate whether activity-level differences are large or small relative to differences for other activities. Activity to activity differences would depend on the coefficients of the I-O table, and thus on the country studied. Relative primary-input contents and primary-input intensities, that is, primaryinput contents and ratios expressed relative to a basis for comparison or standard, additionally would depend on the effects that the selected measure would have on the standard. Finally, different methods may also affect the ranking of activities according to primary-input intensities.

The question for applied research is whether differences resulting from applying these different methods are relevant in practice. That is, whether they may significantly affect the results of H-O tests (Leamer and Levinsohn, 1994) in general, and related studies on the effects of trade regimes on the primary-input intensity of exports (Londero and Teitel, 1996; Londero, Teitel et al., 1998; Moreira and Najberg, 2000) insofar as high-rent-content products are involved. Empirical studies on the effects of alternative measures of rent content are thus useful to shed light on the practical implications of using different methods. This study takes advantage of detailed Argentine data to compare the effects of using these methods on relative primary-input contents, primaryinput intensities, and the ranking and classification of activities according to primaryinput intensities.

\section{Making the alternative methods comparable}

Vanek's method refers to the primary-input content of final demand, while the other methods look at the primary-input content of value of production, the so-called "flow method". Calculations according to the "flow method" are based on total value requirements, that is 


$$
\mathbf{F}^{*}=\left[f_{h j}^{*}\right]=\mathbf{F}(\mathbf{I}-\mathbf{A})^{-1}
$$

where $\mathbf{F}=\left[f_{h j}\right]$ is the matrix containing the direct value requirements of primary input $h$ per unit value of activity $j$, and $\mathbf{A}=\left[a_{i j}\right]$ is the production of $i$ directly required per unit value of production of $j$. To make comparisons among methods possible, in this section all methods will be set according to the primary-input content of value of production.

Table 1. Changes in the I-O tables required to make the results comparable among methods

\begin{tabular}{||l|l|l||}
\hline \hline Method & \multicolumn{1}{|c|}{ A matrix } & \multicolumn{1}{c|}{ F matrix } \\
\hline $\begin{array}{l}\text { Vanek's resource } \\
\text { products }\end{array}$ & $\begin{array}{l}\text { Excludes rows and columns } \\
\text { corresponding to resource- } \\
\text { product activities }\end{array}$ & $\begin{array}{l}\text { Includes rows of resource-product inputs as } \\
\text { nonproduced inputs }\end{array}$ \\
\hline $\begin{array}{l}\text { Postner's } \gamma \text { proportion of } \\
\text { the value of production } \\
\text { of resource-product } \\
\text { activities }\end{array}$ & Same as original & $\begin{array}{l}\text { Includes an additional row containing a } \\
\text { proportion } \gamma \text { of the value of production of the } \\
\text { resource-product activities. That proportion } \\
\text { is deducted from the gross operating surplus }\end{array}$ \\
\hline $\begin{array}{l}\text { Gross operating surplus } \\
\text { of resource-product } \\
\text { activities }\end{array}$ & Same as original & $\begin{array}{l}\text { Includes an additional row to treat gross } \\
\text { operating surplus of resource-product } \\
\text { activities as a different nonproduced input. }\end{array}$ \\
\hline
\end{tabular}

Vanek's method may be implemented by reassigning all lines corresponding to resource-product activities from $\mathbf{A}$ to $\mathbf{F}$ and eliminating the corresponding columns, thus obtaining $\mathbf{A}^{\mathrm{v}}$ and $\mathbf{F}^{\mathrm{v}}$. An equivalent to Postner's method is obtained by imputing a fixed percentage $y$ as the rent content of all resource-product activities and netting it out from the gross operating surplus of these activities. Then we will have the original A matrix and a modified $\mathbf{F}^{\mathrm{P}}$ matrix for primary inputs and transfers. Finally, when gross operating surplus of the resource-product activities is used as a proxy for the rent content, an additional line in $\mathbf{F}$ is used to register the corresponding values, thus obtaining a modified $F^{\text {gos }}$ matrix.

In sum, only Vanek's method results in a different $\mathbf{A}$ matrix, while all methods require an additional row in the $\mathbf{F}$ matrix containing the selected proxy for the direct rent content. Table 1 provides a summary of the three approaches and their implications for 
the I-O matrix. The next section compares the results of calculating relative primaryinput contents and intensities of manufacturing activities according to these three methods.

\section{Measuring primary-input intensity}

When calculating relative primary-input contents and primary-input intensities, it would be desirable to use a standard for comparison that would be independent of the method used. For example, total capital use, the total wage bill and total rent. However, such data is normally not available. A second approach would be to select a standard derived from the data, which would consequently be affected by the method used. That could be the case of total value added classified by capital use, wages and rents. Its disadvantage for the study of nonresource-product activities is that when the weight of primary activities is high, as in a natural-resource rich country like Argentina, the standard of comparison changes significantly from one method to another due to the relative weight of primary activities. For these reasons, in this study the total primary input content of the overall manufacturing sector is used as the standard to calculate relative primary-input contents and primary-input intensities of manufacturing industries. The overall manufacturing sector is operationally defined as the sum of all columns corresponding to that sector.

The primary-input intensity of an industry was calculated as the ratio between two of its total primary-input requirements relative to the same ratio for the overall manufacturing sector. Thus, if $f_{r j}^{*}$ is the coefficient of estimated total rent content in activity $j(j=1, \ldots, n), f_{k j}^{*}$ is that of estimated total capital content, and $f_{w j}^{*}$ is that of estimated total wage content, it is said that $j$ is intensive in rent with respect to labor if

$$
r w_{j}=\frac{f_{r j}^{*} / f_{w j}^{*}}{f_{r, \text { man }}^{*} / f_{w, \text { man }}^{*}}>1
$$

where $f_{h, \text { man }}^{*}$ is the total requirement of primary input $h$ per unit value for the overall 
manufacturing sector. Similarly, it is said that the industry $j$ is intensive in capital with respect to labor if

$$
k w_{j}=\frac{f_{k j}^{*} / f_{w j}^{*}}{f_{k, \text { man }}^{*} / f_{w, \text { man }}^{*}}>1
$$

Finally, it is said that industry $j$ is intensive in capital with respect to rent when

$$
k r_{j}=\frac{f_{k j}^{*} / f_{r j}^{*}}{f_{k, \text { man }}^{*} / f_{r, \text { man }}^{*}}>1
$$

Relative primary input intensities may be expressed as ratios between relative primary input contents. For example, capital-labor relative intensities may be expressed as the ratio of the relative capital content to the relative labor content:

$$
k w_{j}=k_{f} / w_{j}=\left(\frac{f_{k j}^{*}}{f_{k, \text { man }}^{*}}\right) /\left(\frac{f_{w j}^{*}}{f_{w, \text { man }}^{*}}\right)
$$

This alternative presentation will help understand the results on relative primary input intensities.

\section{Comparing methods empirically}

Relative primary-input contents and primary-input intensities were calculated for all manufacturing industries in Argentina using the detailed 1973 I-O table prepared by the Secretaría de Planificación (1986) as revised by Remes Lenicov (1987). This table was specially adapted by for estimating the primary-input content of exports of manufactures (Londero and Teitel, 1996; Londero, Remes and Teitel, 1998). It consists of 211 industries, 172 of which correspond to manufacturing activities, ${ }^{5}$ and 12 lines for imports

\footnotetext{
${ }^{5}$ Manufactures defined according to ISIC, the International Standard Industrial Classification (United Nations, 1971). Londero (1998) compares exports according to ISIC and SITC-based definitions of manufactures.
} 
and value added. Calculations were performed for four alternative measures: Vanek's, Postner's for $\gamma=0.10$ and for $\gamma=0.20,{ }^{6}$ and GOSRPA. ${ }^{7}$ Then, several indicators of agreement between pairs of measures were calculated. This section presents the results of such comparison.

\subsection{Effects on relative primary-input contents}

Two approaches were used to explore whether different methods would result in different measures of relative primary-input contents. First, points representing the relative primary-input content with respect to the aggregate manufacturing sector

$$
\left(f_{k j}^{*} / f_{k, \text { man }}^{*} ; f_{r j}^{*}\right) /\left(f_{r, \text { man }}^{*} ; f_{w j}^{*} / f_{w, \text { man }}^{*}\right)
$$

were calculated for each industry $j$. Then, the distance between a point calculated using one method and the corresponding point calculated using another method was taken as an indicator of the discrepancy between methods. That distance is represented by segment $A B$ in Figure 1. If any two methods provided the same relative primary-input contents, the distance between any two corresponding points would be zero.

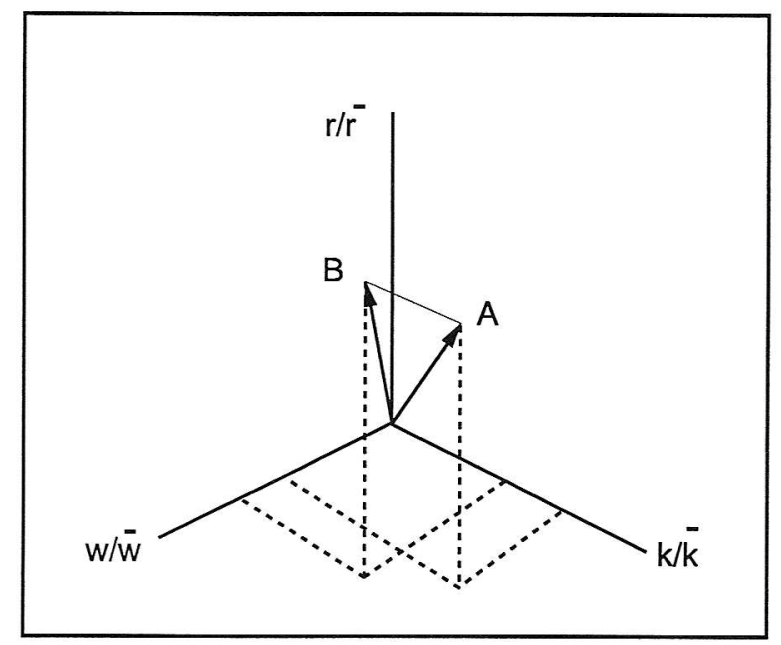

Figure 1. Distance between relative primary input contents.

The second approach focuses in the distribution of the relative primary-input industries.

${ }^{6}$ The upper bound for $\gamma$ is close to the lowest gross operating surplus coefficient for the resource-product

${ }^{7}$ The following industries were classified as producers of "resource products": wool, cotton, wheat, maize, fruits, vegetables, barley, hops, tea, rice, mate, milk, millet, other farm products, cattle, oilseeds, sugar cane, tobacco, fish, forest products, sorghum, birdseed, oat, other industrial crops, coal, petroleum and gas, iron ore, nonferrous metallic minerals, stone, sand, clay, minerals for fertilizers, salt, and other nonmetallic minerals. 
contents, that is the distribution of the primary-input content of industries relative to that of the overall manufacturing sector, which is a weighted average of all 172 manufacturing industries. Therefore, the distribution of relative primary-input contents around that weighted average will depend not only on the effects of methods on the primary-input content of industries, but also on the weight of each industry in the total. ${ }^{8}$ In Argentina, the primary-input composition of the overall manufacturing sector is heavily influenced by resource-intensive food industries.

Table 2. Argentina. Distance between points representing different measures of relative primary-input content: averages, coefficients of variation, skewness and kurtosis.

\begin{tabular}{|c|c|c|c|}
\hline & Postner $(\gamma=0.10)$ & Postner $(\gamma=0.20)$ & GOSRPA \\
\hline Vanek & $\begin{array}{cl}0.62 & (108) \\
s=6.4 & k=52\end{array}$ & $\begin{array}{rl}0.47 & (82) \\
s=5.8 & k=45\end{array}$ & $\begin{array}{rl}0.29 & (64) \\
s=3.0 & k=12\end{array}$ \\
\hline Postner $(\gamma=0.10)$ & - & $\begin{array}{cl}0.19 & (164) \\
s=6.4 & k=51\end{array}$ & $\begin{array}{cl}0.44 & (136) \\
s=6.0 & k=46\end{array}$ \\
\hline Postner $(\gamma=0.20)$ & - & - & $\begin{array}{cc}0.27 & (112) \\
s=5.6 & k=38\end{array}$ \\
\hline
\end{tabular}

Note: Coefficients of variation (percentages) between parentheses; $s$ denotes skewness measured by $\mu_{3} / \sigma_{3}, s>0$ indicates mean $>$ median; $k$ denotes kurtosis measured by $\left(\mu_{4} / \sigma_{4}\right)-3, k>0$ indicates a leptokurtic (peaked) distribution.

The results for distances between points, presented in Table 2, show that different methods provide significantly different results, and that variances are high with respect to the mean. The distributions of these distances are all highly peaked (high kurtosis $k$ ) and heavily skewed to the right $(s>0$, inplying mean $>$ median). Two examples are provided as Figures 2 and 3.

As for different methods, average distances between Postner's method and all others are the greatest, and the distributions are more skewed and peaked. The smallest average distance is between the two Postner measures considered, but even here the

\footnotetext{
${ }^{8}$ That would not be the case if relative contents were measured with respect to a standard that were independent of the method selected, e.g. a ratio between an independently estimated total capital use and an equally independently estimated total wage bill.
} 


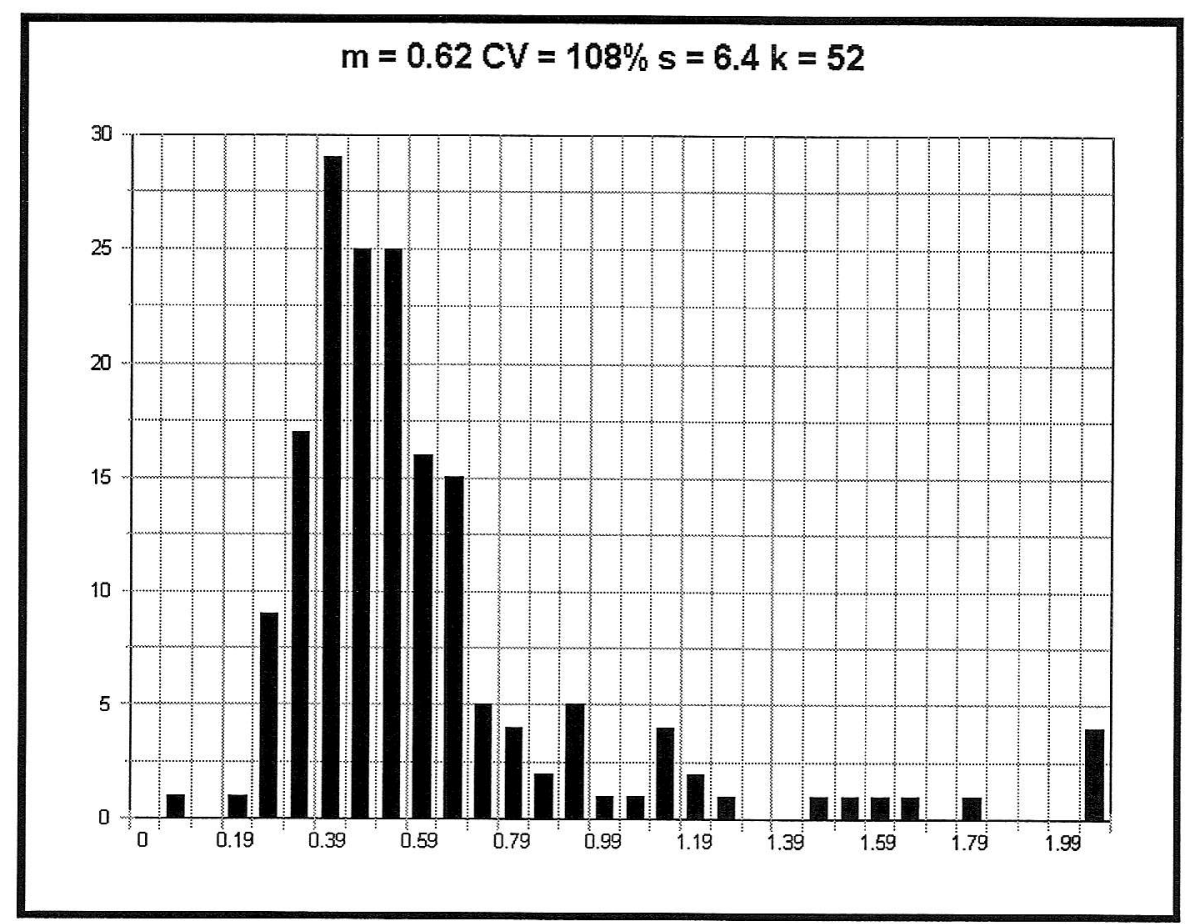

Figure 2. Distribution of Vanek to Postner (0.10) distances.

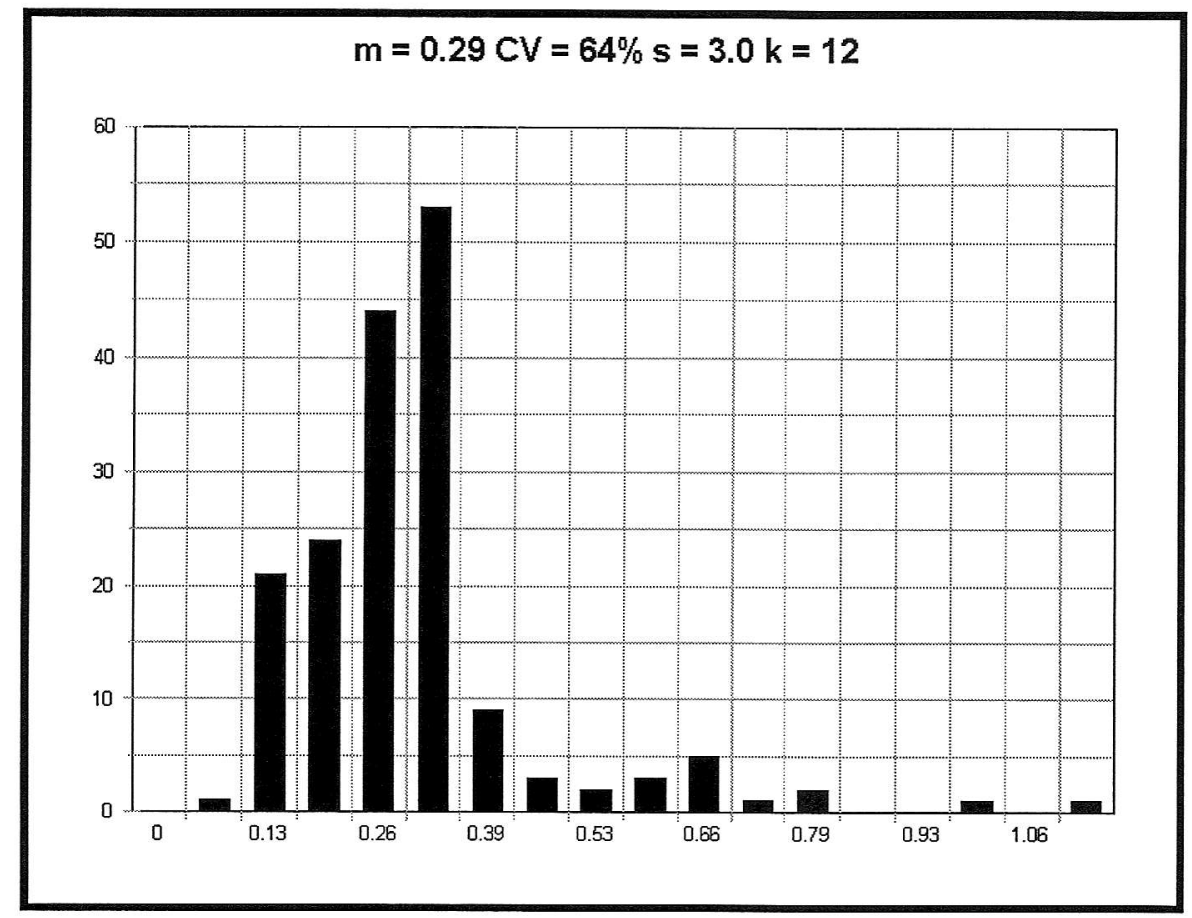

Figure 3. Distribution of Vanek to GOSRPA distances. 
coefficient of variation is very high. The highest three average distances involve one Postner measure, and if the average distance between the two Postner measures is excluded, only one average distance where a Postner measure is involved is not among the greatest three. The average distance between the other two methods is smaller, presents a smaller coefficient of variation, and the distribution is less skewed and less peaked.

It was mentioned above that only one average distance where a Postner measure is involved is not among the greatest three. That is the case of the average distance between Postner and GOSRPA. A greater $\gamma$ value reduces the distance between the Postner and the GOSRPA methods, since a greater share of the gross operating surplus of the resource-product industries is defined as constituting rent under the Postner method. Variability of this average distance, however, is high even for the highest value of $\gamma$ considered.

The relative primary-input contents defined in equation (6) are the underlying determinants of these results. Their key characteristics are summarized in Table 3. First, average relative wage and capital contents are higher when measured using Vanek's method. This is because more wage and capital content is omitted from one industry the greater its use of resource products, and in Argentina a few resource-product intensive industries account for a high share in total manufacturing. Therefore, relative to the other methods, there is a significant omission of wage and capital content from the overall manufacturing sector (common denominator), and significant omissions of wage content for only a few of the industries, leading to an above one average of the individual industries, and a peaked distribution skewed to the left $(s<0$, mean $<$ median). Conversely, Vanek's method adds relatively more "rent" than other methods to total manufacturing, but that "rent" is concentrated in relatively few industries leading to a below one average for all industries.

Relative wage contents are identical when using Postner or GOSRPA methods, since both methods use the full information available on wage content. As a result, all 
Table 3. Argentina. Ratios between relative primary-input contents according to different measures: averages, coefficients of variation, skewness and kurtosis.

\begin{tabular}{|c|c|c|c|c|}
\hline Numerator & Denominator & Postner $(\gamma=0.10)$ & Postner $(\gamma=0.20)$ & GOSRPA \\
\hline \multicolumn{5}{|l|}{ Vanek } \\
\hline$w_{j}^{m} / w_{j}^{2}$ & & $\begin{array}{cc}1.11 & (19) \\
s=-2.0 & k=3.3\end{array}$ & $\begin{array}{cc}1.11 \quad(19) \\
s=-2.0 \quad k=3.3\end{array}$ & $\begin{array}{cc}1.11 & (19) \\
s=-2.0 & k=3.3\end{array}$ \\
\hline$k_{j}^{m} / k_{j}^{z}$ & & $\begin{array}{cc}1.24 & (19) \\
s=-2.2 & k=4.9\end{array}$ & $\begin{array}{cl}1.19 & (16) \\
s=-2.5 & k=6.9\end{array}$ & $\begin{array}{rl}1.04 & (7) \\
s=-3.2 & k=11\end{array}$ \\
\hline$r_{j}^{m} / r_{j}^{z}$ & & $\begin{array}{cc}0.92 & (55) \\
s=0.0 \quad k=-1.7\end{array}$ & $\begin{array}{cc}0.88 \quad(43) \\
s=-0.2 \quad k=-1.7\end{array}$ & $\begin{array}{cc}0.96 \quad(25) \\
s=1.3 \quad k=3.1\end{array}$ \\
\hline \multicolumn{5}{|c|}{ Postner $(\gamma=0.10)$} \\
\hline$w_{j}^{m} / w_{j}^{z}$ & & 1.00 & 1.00 & 1.00 \\
\hline$k_{j}^{m} / k_{j}^{z}$ & & 1.00 & $\begin{array}{cc}0.97 \quad(4) \\
s=2.3 \quad k=5.7\end{array}$ & $\begin{array}{ll}0.88 \quad(33) \\
s=7.6 \quad k=75\end{array}$ \\
\hline$r_{j}^{m} / r_{j}^{z}$ & & 1.00 & $\begin{array}{c}1.11 \quad(25) \\
s=0.2 \quad k=-1.7\end{array}$ & $\begin{array}{cc}1.51 & (55) \\
s=0.5 \quad k=-1.5\end{array}$ \\
\hline \multicolumn{5}{|c|}{ Postner $(\gamma=0.20)$} \\
\hline$w_{j}^{m} / w_{j}^{z}$ & & - & 1.00 & 1.00 \\
\hline$k_{j}^{m} / k_{j}^{z}$ & & - & 1.00 & $\begin{array}{ll}0.91 \quad(28) \\
s=8.6 \quad k=90\end{array}$ \\
\hline$r_{j}^{m} / r_{j}^{z}$ & & - & 1.00 & $\begin{array}{cc}1.26 & (32) \\
s=0.3 \quad k=-1.5\end{array}$ \\
\hline
\end{tabular}

Note: Coefficients of variation (percentages) between parentheses; $s$ denotes skewness measured by $\mu_{3} / \sigma_{3}, s>$ zero shows mean $>$ median; $k$ denotes kurtosis measured by $\left(\mu_{4} / \sigma_{4}\right)-3, k>0$ indicates a leptokurtic (peaked) distribution.

ratios of relative wage contents involving a Vanek measure are equal.

Average ratios of relative rent contents calculated with Postner's method in the numerator are higher the lower is $\gamma(1.5>1.26,1 / 0.88>1 / 0.92)$. Also, ratios of Postner to GOSRPA are always higher than one $(1.5,1.26)$. Theses characteristics are also explained by the relative importance of resource-product-using activities in Argentina's manufacturing. A greater $\gamma$ adds more to the rent content of the overall manufacturing sector, where resource-product-using industries carry a high weight, than to the average of 
individual industries, since the number of resource-product intensive industries is relatively small.

\subsection{Effects on primary-input intensities}

Relative primary-input contents are significantly affected by the method used and the distribution of these differences show high coefficients of variation, suggesting that primary-input intensities would also be affected. To find out, primary-input intensities $k w_{j}^{m}, r w_{j}^{m}$, and $k r_{j}^{m}$ were calculated for all industries $j$ and methods $m$, and the results using one measure

were expressed relative to those using each of the others. Then, standard descriptive statistics of the resulting ratios were calculated. If any two methods were to give the same primary-input intensities, the corresponding average ratio would be equal to one and the coefficient of variation equal to zero. If primary-input intensities calculated using one method differed from those using another method in a fixed proportion $\delta$, then the average ratio would be equal to $1+\delta$ and the coefficient of variation would be equal to zero.

Note that these are ratios between primary-input intensities calculated with respect to the overall manufacturing sector. Therefore, changing the method affects the primary-input content of the industry, as well as that of the standard. For example, in the case of capital-labor ratios of methods $V$ and $P$

$$
k w_{j}^{V} / k w_{j}^{P}=\frac{f_{k j}^{* V} / f_{w j}^{* V}}{f_{k j}^{* P} / f_{w j}^{* P}} \frac{f_{k, \text { man }}^{* P} / f_{w, \text { man }}^{* P}}{f_{k, \text { man }}^{* V} / f_{w, \text { man }}^{* V}}
$$

Consequently, an increase in $f_{k j}^{* V} / f_{w j}^{* V}$ with respect to $f_{k j}^{* P} / f_{w j}^{* P}$ may be compensated by an equivalent increase in the corresponding ratio for the overall manufacturing sector.

The results, presented in Table 4, reflect those presented on relative primary-input contents (Table 3), since each individual ratio between primary input intensities is also the ratio between the corresponding relative primary-input contents. Most average ratios 
between capital-labor intensities $(k w)$ are close to one, ranging from a lowest 0.88 to a highest 1.12. These ratios also show the lowest coefficients of variation, ranging from 4 to 29 percent, since for most manufactures the capital and labor content originating in primary sectors is relatively small. The four average ratios that are the farthest apart from one involve at least one of the two Postner measures, while the average ratio between the two Postner measures and the Vanek to GOSRPA are the two closest to one. The Postner to Postner ratio, however, shows a very low coefficient of variation. These results suggest that for this I-O table the value of $y$ does not significantly affect capital-labor intensity measures. As it should be expected, increasing the value of $\gamma$ brings Postner measures closer to GOSRPA because a greater share of the gross operating surplus is classified as rent.

The effects on ratios of rent-labor intensities are, overall, greater than those on ratios of capital-labor intensities. Averages ratios for rent-labor intensities are farther apart, and coefficients of variation are higher. Values range from a lowest 0.90 to a highest 1.51 , compared to a 0.88 to 1.12 range for capital to labor intensities.

Distributions are in general less skewed and less peaked. The two highest values involve Postner to GOSRPA measures and are due to the effects of relative rent contents, since relative labor contents are identical (Table 3).

The highest average ratios and coefficients of variation are found among ratios between capital-rent intensities. Average ratios range from a lowest 0.83 to a highest 2.40 , and coefficients of variation from 25 to 195 percent. While the greatest values continue to be for pairs including a Postner measure, these results also show a high averages for the Vanek-GOSRPA pair. Capital-rent ratios of Vanek's measures are relatively high reflecting the high values of relative capital contents and the low values of relative rent contents in Table 3. Similarly, the low values of capital-rent contents for

The highest average ratios and coefficients of variation are found among ratios between capital-rent intensities. Average ratios range from a lowest 0.83 to a highest 2.40 , and coefficients of variation from 25 to 195 percent. While the greatest values 
Table 4. Argentina. Ratios between primary-input intensities according to different measures: averages, coefficients of variation, skewness and kurtosis.

\begin{tabular}{|c|c|c|c|c|}
\hline Numerator & Denominator & Postner $(y=0.10)$ & Postner $(\gamma=0.20)$ & GOSRPA \\
\hline \multicolumn{5}{|l|}{ Vanek } \\
\hline$k w_{j}^{m} / k w_{j}^{z}$ & & $\begin{array}{cl}1.12 & (19) \\
s=3.4 & k=27\end{array}$ & $\begin{array}{rl}1.09 & (21) \\
s=4.3 & k=29\end{array}$ & $\begin{array}{rl}0.98 & (26) \\
s=4.4 & k=22\end{array}$ \\
\hline$r w_{j}^{m} / r w_{j}^{z}$ & & $\begin{array}{cc}0.98 & (88) \\
s=1.8 & k=4.2\end{array}$ & $\begin{array}{cc}0.90 & (65) \\
s=1.9 \quad k=4.7\end{array}$ & $\begin{array}{rl}0.96 & (58) \\
s=3.2 & k=12\end{array}$ \\
\hline$k r_{j}^{m} / k r_{j}^{z}$ & & $\begin{array}{cc}2.40 & (195) \\
s=0.7 & k=-0.9\end{array}$ & $\begin{array}{cc}1.81 \quad(109) \\
s=0.6 \quad k=-1.0\end{array}$ & $\begin{array}{c}1.15 \quad(29) \\
s=0.1 \quad k=-0.5\end{array}$ \\
\hline \multicolumn{5}{|c|}{ Postner $(\gamma=0.10)$} \\
\hline$k w_{j}^{m} / k w_{j}^{z}$ & & 1.00 & $\begin{array}{cc}0.97 \quad(4) \\
s=2.3 \quad k=5.7\end{array}$ & $\begin{array}{cl}0.88 & (29) \\
s=7.6 & k=75\end{array}$ \\
\hline$r w_{j}^{m} / r w_{j}^{z}$ & & 1.00 & $\begin{array}{cc}1.11 \quad(28) \\
s=0.2 \quad k=-1.7\end{array}$ & $\begin{array}{cc}1.51 \quad(83) \\
s=0.5 \quad k=-1.5\end{array}$ \\
\hline$k r_{j}^{m} / k r_{j}^{z}$ & & 1.00 & $\begin{array}{cc}0.93 \quad(25) \\
s=0.2 \quad k=-1.4\end{array}$ & $\begin{array}{cl}0.87 & (87) \\
s=6.6 & k=65\end{array}$ \\
\hline \multicolumn{5}{|c|}{ Postner $(\gamma=0.20)$} \\
\hline$k w_{j}^{m} / k w_{j}^{z}$ & & - & 1.00 & $\begin{array}{cl}0.91 & (25) \\
s=8.6 & k=90\end{array}$ \\
\hline$r w_{j}^{m} / r w_{j}^{z}$ & & - & 1.00 & $\begin{array}{c}1.26 \quad(41) \\
s=0.3 k=-1.5\end{array}$ \\
\hline$k r_{j}^{m} / k r_{j}^{2}$ & & - & 1.00 & $\begin{array}{rl}0.83 & (59) \\
s=7.5 & k=79\end{array}$ \\
\hline
\end{tabular}

Note: Coefficients of variation (percentages) between parentheses; $s$ denotes skewness measured by $\mu_{3} / \sigma_{3}, s>$ zero shows mean $>$ median; $k$ denotes kurtosis measured by $\left(\mu_{4} / \sigma_{4}\right)-3, k>0$ indicates a leptokurtic (peaked) distribution.

continue to be for pairs including a Postner measure, these results also show a high averages for the Vanek-GOSRPA pair. Capital-rent ratios of Vanek's measures are relatively high reflecting the high values of relative capital contents and the low values of relative rent contents in Table 3. Similarly, the low values of capital-rent contents for Postner estimates reflect the high relative rent contents and low relative capital contents shown in Table 3. These results suggest that rankings according to capital to rent intensities could be those most affected by the method chosen. 
Overall, average ratios involving at least one Postner measure are affected the most. When Postner measures are excluded, average capital-rent and rent-labor ratios tend to be closer to one and coefficients of variation tend to be smaller. These characteristics are considerably less pronounced for capital-labor ratios.

\subsection{Correlations between pairs of measures}

Another way of looking at the effects on primary-input intensities would be to analyze the association between measures resulting from different methods. If any two methods provided the same results there should be a perfect correlation between measures along a straight line going through the origin with a $45 \circ$ angle. More precisely, if methods $V$ and $P$ provided identical results, regressing the measures from one method against those of the other for each industry $j$

$$
k w_{j}^{V}=\alpha+\beta k w_{j}^{P}
$$

would result in $\alpha=0, \beta=1$, and $R^{2}=1$. If $\alpha \neq 0$, but $\beta=1$ and $R^{2}=1$, rankings according to primary input intensities would not be affected..

The coefficients from the regressions for all pairs of methods are shown in Table 5 , including the standard errors of the coefficients (between parentheses), $F$ values for the test $\alpha=0$ and $\beta=1$, and $\mathrm{R}^{2} \mathrm{~s}$.

The results show that no pair of methods is highly correlated along a straight line going through the origin with a $45 \circ$ angle for all three primary-input intensities. For most pairs of methods, all three hypotheses of $\alpha=0$ and $\beta=1$ must be rejected. In only two regressions this hypothesis cannot be rejected at the 5 percent level, and these regressions correspond to different pairs of methods. Even in the two cases that the hypothesis cannot be rejected, $\mathrm{R}^{2}$ values are low. Moreover, in the case of this I-O table individual primary input intensities estimated according to one method are poor predictors of such intensities estimated according to other methods. With only one exception ( $k w$, Postner to Postner), estimated coefficients that result very close to $\beta=1( \pm 0.05)$ are associated 
Table 5. Argentina: Linear regressions between pairs of measures of primary-input intensity.

\begin{tabular}{|c|c|c|c|c|}
\hline & Independent & Postner $(\gamma=0.10)$ & Postner $(\gamma=0.20)$ & GOSRPA \\
\hline Dependent & & $\alpha \quad \beta$ & $\alpha \quad \beta$ & $\alpha \quad B$ \\
\hline \multicolumn{5}{|l|}{ Vanek } \\
\hline$k w_{j}$ & & $\begin{array}{cc}0.14 & 0.97 * \\
(0.056) & (0.055) \\
F=17 \quad \mathrm{R}^{2}=0.64\end{array}$ & $\begin{array}{cc}0.10 * & 0.97 * \\
(0.056)(0.053) \\
F=9 \quad \mathrm{R}^{2}=0.66\end{array}$ & $\begin{array}{cc}0.11^{*} & 0.86 \\
(0.057) & (0.048) \\
F=7 \quad \mathrm{R}^{2}=0.65\end{array}$ \\
\hline$r w_{j}$ & & $\begin{array}{cc}0.46 & 0.30 \\
(0.101) & (0.067) \\
F=54 \quad \mathrm{R}^{2}=0.11\end{array}$ & $\begin{array}{cc}0.22 & 0.73 \\
(0.094) & (0.084) \\
F=5.5 \mathrm{R}^{2}=0.31\end{array}$ & $\begin{array}{cc}-0.03 * & 1.30 \\
(0.062)(0.065) \\
F=14 \mathrm{R}^{2}=0.71\end{array}$ \\
\hline$k r_{j}$ & & $\begin{array}{c}0.521 .75 \\
(0.431)(0.071) \\
F=103 \mathrm{R}^{2}=0.78\end{array}$ & $\begin{array}{cc}0.43 & 1.59 \\
(0.287) & (0.041) \\
F=182 \mathrm{R}^{2}=0.90\end{array}$ & $\begin{array}{cc}0.34 & 1.13 \\
(0.111) & (0.011) \\
F=140 \mathrm{R}^{2}=0.98\end{array}$ \\
\hline \multicolumn{5}{|c|}{ Postner $(\gamma=0.10)$} \\
\hline$k w_{j}$ & & - & $\begin{array}{cc}-0.02 * & 0.99 \\
(0.010) & (0.009) \\
F=51 & \mathrm{R}^{2}=0.99\end{array}$ & $\begin{array}{cc}0.18 & 0.70 \\
(0.049) & (0.042) \\
F=72 \quad \mathrm{R}^{2}=0.62\end{array}$ \\
\hline$r w_{j}$ & & - & $\begin{array}{cc}-0.15 & 1.37 \\
(0.033)(0.030) \\
F=80 \quad \mathrm{R}^{2}=0.93\end{array}$ & $\begin{array}{c}0.08^{*} 1.12^{*} \\
(0.092)(0.096) \\
F=2.4 \mathrm{R}^{2}=0.44\end{array}$ \\
\hline$k r_{j}$ & & - & $\begin{array}{cc}0.25 & 0.83 \\
(0.077) & (0.011) \\
F=137 \mathrm{R}^{2}=0.97\end{array}$ & $\begin{array}{cc}0.54 & 0.53 \\
(0.168) & (0.016) \\
F=547 \mathrm{R}^{2}=0.86\end{array}$ \\
\hline \multicolumn{5}{|c|}{ Postner $(\gamma=0.20)$} \\
\hline$k w_{j}$ & & - & - & $\begin{array}{cc}0.14 & 0.76 \\
(0.042) & (0.036) \\
F=63 \quad \mathrm{R}^{2}=0.73\end{array}$ \\
\hline$r w_{j}$ & & - & - & $\begin{array}{c}0.08 * 0.98 * \\
(0.048)(0.050) \\
F=1.5 \mathrm{R}^{2}=0.69\end{array}$ \\
\hline$k r_{j}$ & & - & - & $\begin{array}{cc}0.22 & 0.66 \\
(0.113)(0.011) \\
F=665 \mathrm{R}^{2}=0.96\end{array}$ \\
\hline
\end{tabular}

Note: *, not statistically different from $0(\alpha)$ or $1(\beta)$ at the $5 \%$ level. Standard errors between parentheses. $F$ statistics from testing $\alpha=0$ and $\beta=1 ; P[F(2,170)>3.00]=0.05$ and $P[F(2,170)>4.61]=0.01$. Actually, tables provide results up to 120 degrees of freedom; the numbers provided correspond to the limit when the degrees of freedom tend to $\infty$. 
with low $R^{2}$ values (below 0.70 ). Conversely, in most of the cases that $R^{2}$ values are high $(>0.90)$, coefficients are not close to one. In conclusion, since most coefficients $\beta$ are different from one, and those that are close to one present relatively low $\mathrm{R}^{2}$, rankings of industries according to primary-input intensities could be affected by the method chosen.

When looking at particular primary-input intensities, an already familiar picture appears. The $\beta$ coefficients that are farther apart from one correspond to pairs that include rent, and the largest differences from one correspond to pairs that include at least one Postner measure.

\subsection{Effects on rankings}

The results presented thus far suggest that rankings based on primary-input intensities could be affected by the method employed. To explore the importance of these effects, two measures of rank correlation were used. First, for each of the three primary-input intensities, Kendall's coefficients of concordance $W$ among the four rankings resulting from the different methods were calculated. ${ }^{9} W$ varies from 0 to 1 , where 1 indicates perfect concordance among all rankings and 0 indicates total disagreement. The results obtained

$$
\begin{aligned}
& W\left(k w_{j}\right)=0.90 \\
& W\left(r w_{j}\right)=0.89 \\
& W\left(k r_{j}\right)=0.88
\end{aligned}
$$

indicate that there is concordance among all methods, and that there is slightly less concordance among primary-input intensities involving rents..$^{10}$ As indicated before, more concordance among capital to labor intensity rankings was to be expected, since for most manufactures the capital and labor contents originating in primary sectors are

\footnotetext{
${ }^{9}$ Kendall (1970) provides a thorough analysis of the rank correlation methods used in this section.

${ }^{10}$ Tests of statistical significance for $W$ are not reported since calculations are based on population data.
} 
relatively small. Concordance, however, is relatively high also for the other primaryinput intensities. The results indicate that in the case of this I-O table, the choice of method does not affect the rankings significantly.

For a more detailed look at the relations between pairs of methods, Kendall's and Spearman's rank correlation coefficients between pairs of methods were also calculated. Both coefficients vary between 1 and -1; one indicates perfect correlation between the two rankings, minus one indicates perfect negative correlation (the first in one ordering is the last in the other), and zero may be regarded as an indication of independence. Both coefficients provide similar, although not identical information. Kendall's $\tau$ uses the sign of the difference between the position of one case in one of the rankings and the position of the same case in the second ranking; consequently, the value of $\tau$ is not affected by the number of positions between the two cases. Spearman's $\rho$ uses the square of the difference between the two positions in the rankings (fifth minus first equals four); thus, it gives greater weight to cases that are farther apart.

The results, presented in Table 6, show a familiar pattern: Vanek's rankings are better correlated with GOSRPA rankings, Postner rankings do not seem to be greatly affected by the value of $\gamma$, and Postner rankings approach the GOSRPA ranking for higher $\gamma$ values. Comparisons involving one Postner measure tend to show lower rank correlations, which tend to be higher among Vanek's and GOSRPA methods.

As for different primary-input intensities, rankings according to capital to labor ratios are less affected by the choice of method. Concordances, however, are lower when GOSRPA method is involved, which is due to the different treatment of gross operating surpluses. The GOSRPA method uses the wage information of the resource-product industries, but allocates all of the gross operating surplus to rents. The other methods either ignore the composition of value added of resource-product industries (Vanek), or allocate part of their gross operating surplus to capital requirements (Postner). 
Table 6. Argentina: Rank correlations between pairs of measures of primary-input intensity.

\begin{tabular}{|c|c|c|c|c|c|c|}
\hline \multirow{3}{*}{ Vanek } & \multirow{2}{*}{\multicolumn{2}{|c|}{$\begin{array}{c}\text { Postner }(y=0.10) \\
\tau \quad \rho\end{array}$}} & \multicolumn{2}{|c|}{ Postner $(\gamma=0.20)$} & \multicolumn{2}{|c|}{ GOSRPA } \\
\hline & & & \multirow[t]{2}{*}{$\tau$} & \multirow[t]{2}{*}{$\rho$} & & \multirow[t]{2}{*}{$\rho$} \\
\hline & & & & & & \\
\hline$k w_{j}$ & 0.79 & 0.88 & 0.79 & 0.88 & 0.73 & 0.84 \\
\hline$r w_{j}$ & 0.52 & 0.67 & 0.68 & 0.84 & 0.85 & 0.97 \\
\hline$k r_{j}$ & 0.49 & 0.63 & 0.67 & 0.83 & 0.87 & 0.98 \\
\hline \multicolumn{7}{|c|}{ Postner $(\gamma=0.10)$} \\
\hline$k w_{j}$ & & & 0.95 & 0.99 & 0.70 & 0.80 \\
\hline$r w_{j}$ & & & 0.84 & 0.96 & 0.62 & 0.79 \\
\hline$k r_{j}$ & & & 0.83 & 0.95 & 0.59 & 0.75 \\
\hline \multicolumn{7}{|c|}{ Postner $(\gamma=0.20)$} \\
\hline$k w_{j}$ & & & & - & 0.75 & 0.84 \\
\hline$r w_{j}$ & & & & - & 0.78 & 0.93 \\
\hline$k r_{j}$ & & & & E & 0.76 & 0.91 \\
\hline
\end{tabular}

Note: Kendall's $\tau_{a}$ and Spearman's $\rho_{a}$, since there are no ties. Tests of statistical significance are not reported since calculations are based on population data.

\subsection{Effects on classifications}

Methods may affect the classification of industries according to their primary-input intensity. This type of classification may be represented graphically using "relative intensity triangles." In these diagrams, the primary-input intensity of an industry with respect to each pair of primary inputs is measured along the triangle's sides. Thus in Figure 4, capital intensity with respect to labor $(k w)$ is measured along the base of the triangle, while the left side measures rent intensity with respect to labor $(r w)$, and the right side capital intensity with respect to rent $(k r) .{ }^{11}$

All industries with the same primary-input intensity with respect to a particular

${ }^{11}$ For a more detailed explanation see Leamer (1987) and (Londero, 1994). 
pair of primary inputs must lie on a line that goes from the relevant point on the triangle's side to the opposite vertex. In Figure 4, for instance, all industries with the same capital intensity with respect to labor, e.g. $k w_{j}$, must lie on the line connecting the top vertex with point $k w_{j}$ on the triangle's base. Therefore, the primary-input intensity of an industry with respect to all three primary inputs is represented by its position at the intersection of two lines of this sort. For example, the point circled in Figure 4 corresponds to an industry that is capital-intensive with respect to labor $k w_{j}$ and rent-intensive with respect to labor $r w_{j}$, implying that the industry is capital intensive with respect to rent (since by definition $\left.k r_{j}=k w_{j} / r w_{j}\right)$.

The triangles can be constructed so that the primary-input intensity of the aggregate manufacturing sector corresponds to the point at the center of an equilateral triangle (the intersection of its three median lines) where $k w=r w=k r=1$. This provides a standard for all other activities, in reference to which the triangle is divided into six regions, according to the primaryinput intensity of the industries concerned. These regions have been numbered from

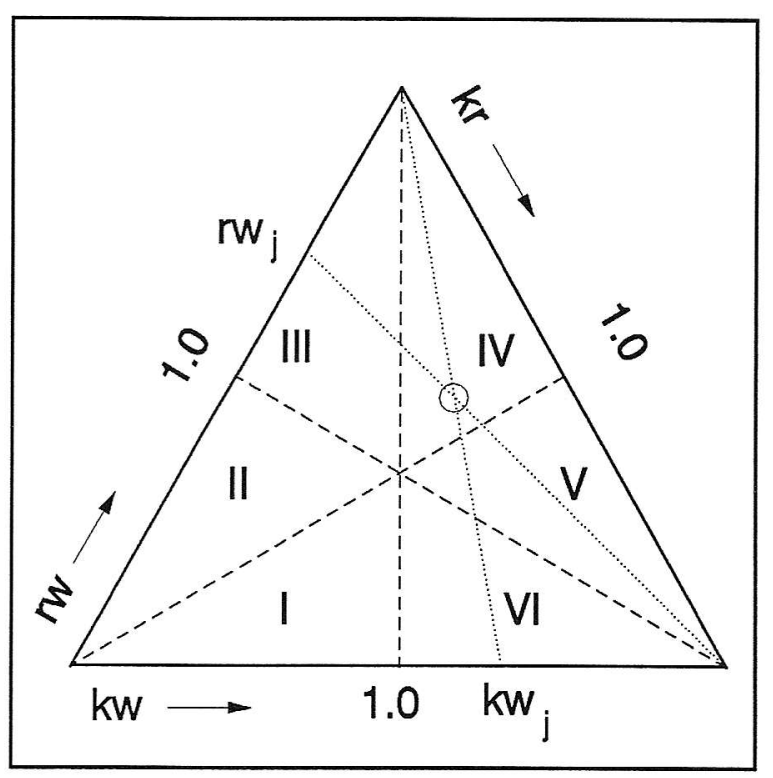

Figure 4. Relative intensity triangle. one to six beginning from the left lower corner and continuing clockwise. Examples of actual triangles for Vanek's and GOSRPA methods are presented as Figures 5 and 6.

To find the effects of different methods on industry classification according to their primary-input intensities, all 172 industries were assigned to their corresponding region, and contingency tables were prepared for all pairs of methods (see Appendix). Then, Cohen's (1960) $\kappa$ was calculated for all tables. $\kappa$ measures the proportion of agreement between two methods, correcting for the possibility of agreement attributable 


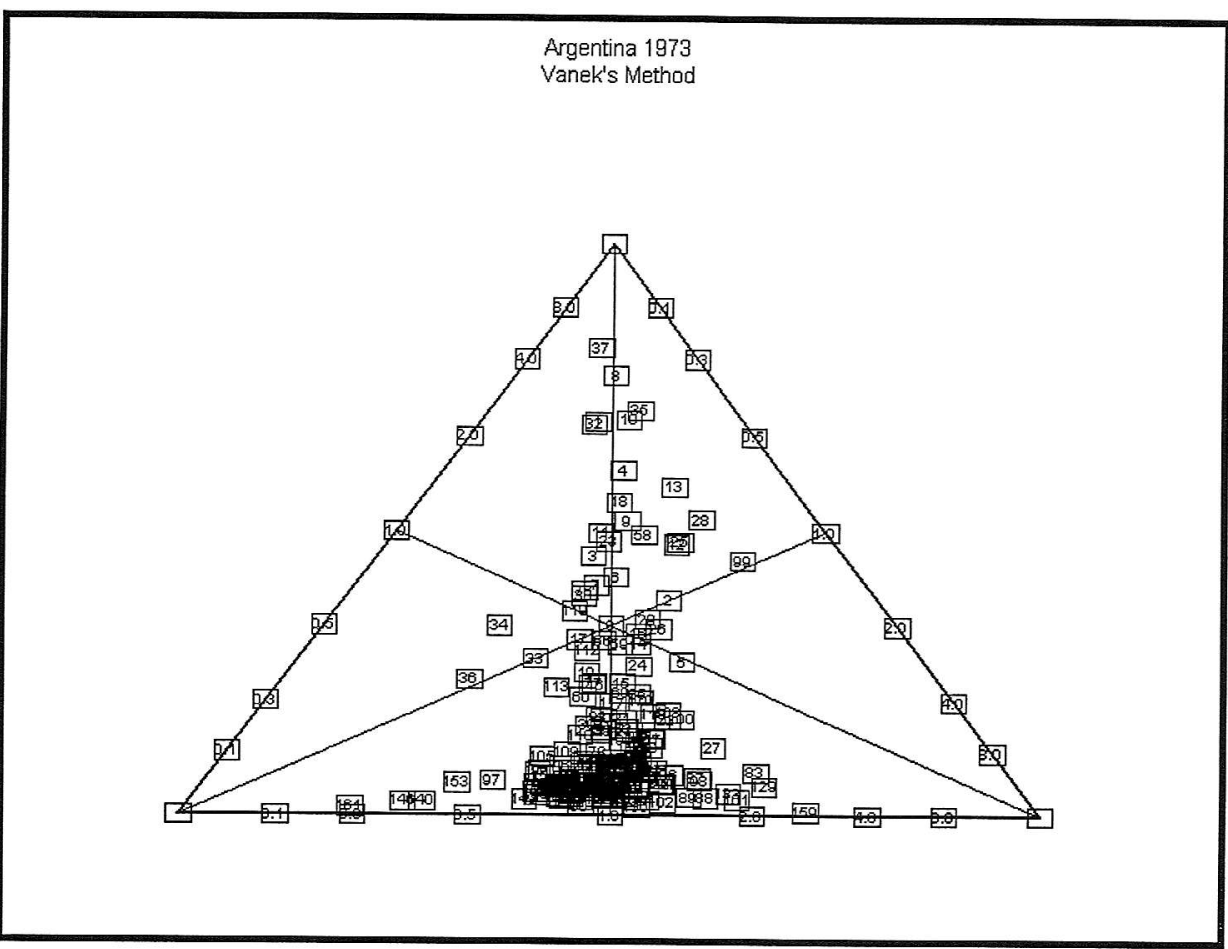

Figure 5. Vanek's method.

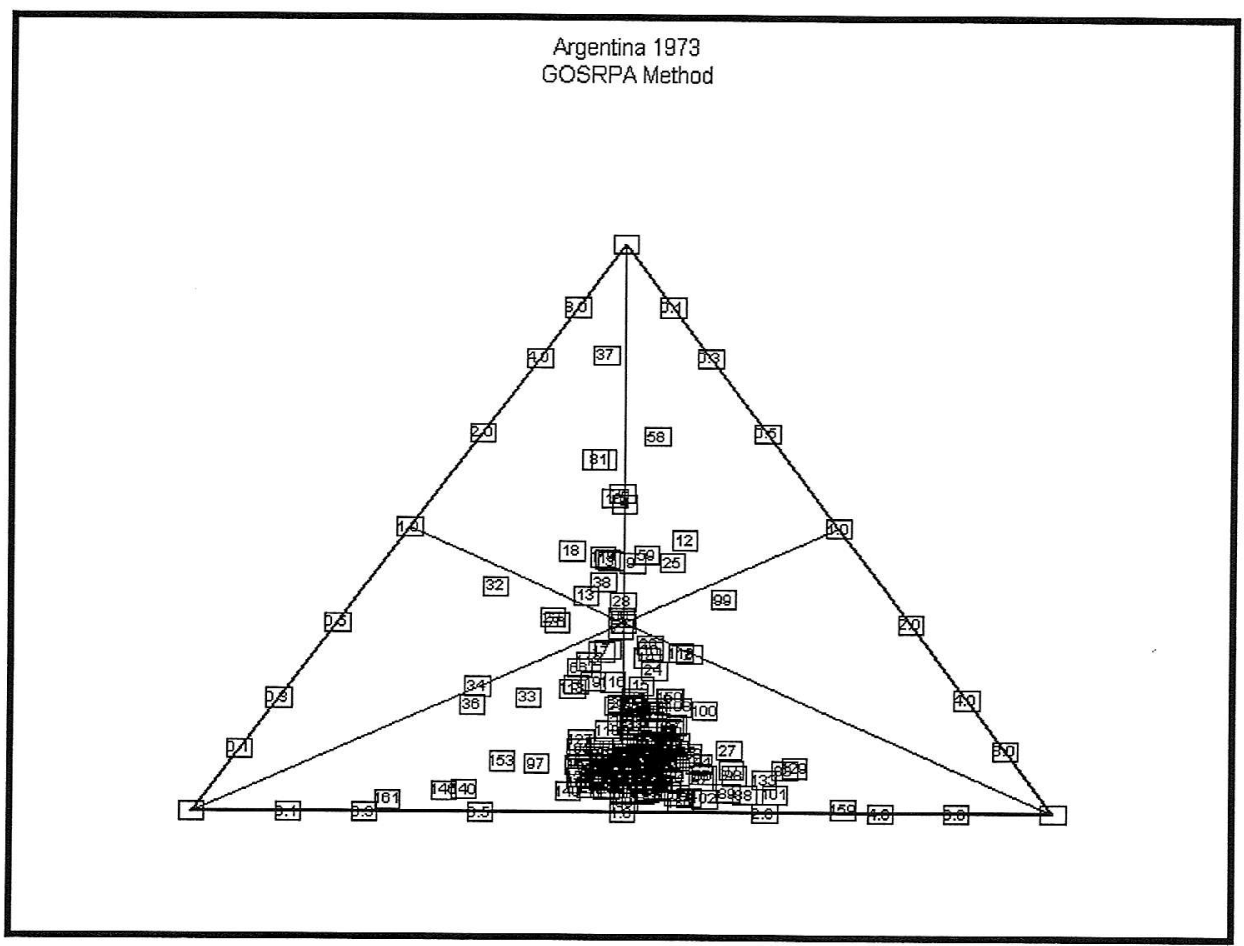

Figure 6. GOSRPA method. 
to chance. Its value is zero when the agreement between the two methods equals that expected by chance alone, it equals one when there is complete agreement between the two methods, and it is negative if the observed agreement is less that what would have been expected just by chance.

The results, presented in Table 6, show that changes in measured primary-input intensities attributable to methods are enough to make many industries switch regions of the triangle. These results suggest that research outcomes grouped by primary input classifications may be significantly affected by the method employed. In general, the highest level of agreement is between the two Postner measures, and the lowest levels correspond to the two Postner-GOSRPA pairs.

A closer look at the contingency tables show that the most important differences in classification, that is, those that explain a great deal of the relatively low values of $\kappa$, result from switches between a region I (labor intensive with respect to a capital, and capital intensive with respect to rent) and region VI (capital intensive with respect to labor, and labor intensive with respect to rent). In particular, Vanek's method classifies as capital intensive with respect to labor (VI) industries that Postner's (0.10 and 0.20) classifies as labor intensive with respect to capital (I); Postner's (0.10) classifies in group I industries that GOSRPA and Postner's (0.20) classify in group VI; Postner's method $(0.20)$ classifies in I industries that GOSRPA classifies in VI. Were it not for these switches from region I to region VI, values of $\kappa$ would be much higher. These classification changes are due primarily to the proximity of industries to the border between the two regions (low variability of capital intensities with respect to labor around 1), allowing for comparatively minor changes in relative primary-input content to result in region switches.

The second important group of changes originates in industries that are rent intensive according to one method (regions III and IV), but are classified differently by other methods. These switches are less affected by proximity to the border and more determined by the change in method. 
These findings suggest that researchers should avoid reporting results exclusively in aggregates according to classifications. Such information should be complemented by other more disaggregated ways that would show proximity to the border, and perhaps with a sensitivity analysis to alternative measures of primary input content as well.

\subsection{Effects on the primary-input intensity of total exports}

Finally, as mentioned in section 1, several tests of the H-O model of international trade have been conducted using I-O techniques. These tests are based on comparing the primary-input content of net trade for different countries with their corresponding primary input endowments. The question is whether alternative measures of rent content may significantly affect the results of the primary-input content of net trade, and thus the tests.

The results on net exports of primary input services are reported in Table 8. As expected from a natural resource rich country, Argentina appears as a net exporter of rents and a net importer of labor services, regardless of the method used. In the case of capital services, instead, it appears as a net importer when using Vanek and GOSRPA methods because both share the characteristic of ignoring the capital content of resource products. When using Postner, instead, Argentina appears as a net exporter of capital services as well.

Primary-input ratios and intensities for exports and imports of manufactures are presented in Table $9,{ }^{12}$ which shows that exports present a high rent to labor intensity, and imports show the exact opposite characteristic. Such is the case under any measure of rent content. However, the ratios between rent-labor intensities of exports and imports vary considerably among methods, suggesting that different results for different methods may be obtained in less natural-resource-rich countries. Capital to labor intensities, instead, differ for different methods. Postner results indicate that exports would be more capital intensive than imports, GOSRPA shows exports less capital intensive than

\footnotetext{
${ }^{12}$ Following the common assumption of identical production techniques, calculations for both exports and imports are made with the same I-O table for illustrative purposes only. For different assumptions, see Trefler (1993) and Davis and Weinstein (1998).
} 
Table 8. Argentina. Value of net exports of primary-input services

\begin{tabular}{||lllr||}
\hline \hline Method & $\mathrm{X}$ & $\mathrm{M}$ & $\mathrm{X}-\mathrm{M}$ \\
\hline Vanek & & & \\
Wages & $4,377,030$ & $6,473,670$ & $-2,096,640$ \\
Capital & $5,385,160$ & $8,264,050$ & $-2,878,890$ \\
Rents & $8,886,690$ & $2,399,540$ & $6,487,150$ \\
Postner $(\gamma=0.10)$ & & & \\
Wages & $6,247,190$ & $7,054,230$ & $-807,040$ \\
Capital & $9,880,370$ & $9,009,630$ & 870,740 \\
Rents & $1,503,250$ & $1,085,980$ & 417,270 \\
Postner $(\gamma=0.20)$ & & & $-807,040$ \\
Wages & $6,247,190$ & $7,054,230$ & 122,000 \\
Capital & $8,977,760$ & $8,855,760$ & $1,166,010$ \\
Rents & $2,405,850$ & $1,239,840$ & \\
GOSRPA & & & $-807,040$ \\
Wages & $6,247,190$ & $7,054,230$ & $-2,251,180$ \\
Capital & $6,222,440$ & $8,473,620$ & $3,539,190$ \\
Rents & $5,161,180$ & $1,621,990$ & \\
\hline \hline
\end{tabular}

imports, and Vanek shows them of about the same intensity. These results reflect those obtained in the preceding section for the classification of exporting sectors: in the case of this I-O table, capital to labor ratios and intensities are sensitive to the method used.

In summary, when looking at the net exports of primary-input services, different methods may lead to different results. Such is the case with the factor intensity of net exports as well.

\section{Conclusions}

Different methods for measuring rent content lead to different estimates of primary-input contents and ratios for the same industry. The effects of these methods on measured relative primary-input contents and primary-input intensities calculated with 
Table 9. Argentina. Primary-input ratios and intensities of trade in manufactures

\begin{tabular}{||l|ccc|cc||}
\hline \multirow{2}{*}{} & \multicolumn{3}{|c|}{ Primary input ratios } & \multicolumn{2}{c||}{ Primary input intensities } \\
\cline { 2 - 6 } & $\mathrm{X}$ & $\mathrm{M}$ & All manuf. & $\mathrm{X}$ & $\mathrm{M}$ \\
\hline Vanek & 1.23 & 1.28 & 1.26 & 0.98 & 1.01 \\
Capital-labor & 2.03 & 0.37 & 1.08 & 1.88 & 0.34 \\
Rent-labor & 0.61 & 3.44 & 1.17 & 0.52 & 2.95 \\
Capital-rent & & & & & \\
Postner $(\gamma=0.10)$ & 1.58 & 1.28 & 1.41 & 1.13 & 0.91 \\
Capital-labor & 0.24 & 0.15 & 0.15 & 1.57 & 1.00 \\
Rent-labor & 6.57 & 8.30 & 9.16 & 0.72 & 0.91 \\
Capital-rent & & & & & \\
Postner $(\gamma=0.20)$ & 1.44 & 1.26 & 1.32 & 1.09 & 0.95 \\
Capital-labor & 0.39 & 0.18 & 0.24 & 1.62 & 0.74 \\
Rent-labor & 3.73 & 7.14 & 5.55 & 0.67 & 1.29 \\
Capital-rent & & & & & \\
GOSRPA & 1.00 & 1.20 & 1.08 & 0.93 & 1.12 \\
Capital-labor & 0.83 & 0.23 & 0.48 & 1.71 & 0.48 \\
Rent-labor & 1.21 & 5.22 & 2.23 & 0.54 & 2.35 \\
Capital-rent & & & & & \\
\hline \hline
\end{tabular}

respect to industry aggregates depend on the characteristics of the I-O table. For the table used in this study, relative primary-input contents and primary-input intensities of manufacturing industries are significantly affected by the method chosen. Postner's method results in the greatest differences when all pairs of methods are compared.

Rankings according to primary-input intensities of the five resulting orderings are less affected than it would have been expected given the sensitivity of intensity measures to the method used. However, consistent with the characteristics observed in that sensitivity, comparisons of rankings between pairs of measures involving Postner's method generally show less concordance than those between pairs that do not involve such method.

Classifications according to primary-input intensity, instead, are more affected 
than rankings by the method chosen, as shown by the low values of many agreement coefficients between pairs of methods. This greater sensitivity of classifications to the method chosen is due primarily, although not exclusively, to switches in classifications according to the capital intensity with respect to labor. These switches originate in the concentration of activities along the border between the two classes. Therefore, when results are presented as total number of products or total value of exports in broad classes according to primary input intensities, these results should be complemented with activity-level information, and if possible with a sensitivity analysis to changes in measurement methods.

This study shows that the method selected may significantly affect estimates of relative primary-input intensities. In particular, the results obtained for relative primary input contents and intensities suggest that studies on the primary-input intensity of trade, and HO tests in particular, may be affected by the method chosen for measuring natural resource content. Therefore, careful consideration should be given to the choice of method before measuring primary-input content. The advantages and disadvantages of these methods should be considered with reference to the specific case. Special attention should be given to this issue when analyzing natural-resource rich countries.

As regards these advantages and disadvantages, Londero (1999) noted that by taking into account current-input and wage coefficients, Postner's and the gross operating surplus of the resource-product activities approaches make the most use of the information provided by an input-output table. It is not, however, possible to issue a blanket recommendation of one method over the other, since the difference between the two would depend on the variability of the true rent coefficients and of the capital-output ratios of the RPA activities, and no independent measures for these characteristics were available for this study. Postner may be preferable when little variability is expected among rent coefficients of resource product activities. GOSRPA would provide better results when there is greater variability in rent coefficients among activities and such variability is reflected in gross operating surplus coefficients because capital coefficients 
are similar or very low relative to rent coefficients.

An alternative method to the ones already discussed would consist of splitting the gross operating surpluses of all resource-product activities in the same proportion. This method would amount to assuming a constant (arbitrary) capital to value-of-naturalresources ratio for all resource-product activities. It would share with Postner and GOSRPA the advantage of preserving the information of the current-input structure, but it will have two additional advantages. First, it would avoid the omission of the capital content of resource-product activities resulting from GOSRPA, but retain its ability of capturing rent variability when it is reflected in that of the gross operating surplus. Second, by imposing the arbitrary assumption on the area of ignorance it would help focus the attention on the correct issue, that is, the shares of rents and reproducible capital costs in the gross operating surplus, rather than the natural-resource to output ratio as in Postner's method.

Finally, it would be important to be able to compare the results of using alternative methods against those based on a reliable and independent measure of direct rent content at the industry level. Such comparisons would require the ability to split the gross operating surplus coefficient in reproducible capital and rent. This composition of the gross operating surplus may be estimated by using farm-capital composition data that distinguishes between reproducible capital and the value of nonreproducible assets. If such data were available, care should be exercised in assessing the effects of existing or potential property taxes on the quality of such data. Comparisons for several I-O tables with different characteristics would also be useful for reaching more definitive conclusions regarding preferences among methods, since primary input intensity results depend on the characteristics of the input-output table. 


\section{Appendix. Contingency tables}

Table B.1. Vanek and Postner $(\gamma=0.10)$ methods

\begin{tabular}{||l|c|c|c|c|c|c|c||}
\hline Vanek's Postner 0.10 & I & II & III & IV & V & VI & Total \\
\hline I & 70 & 2 & 3 & & & & 75 \\
\hline II & 3 & & 1 & & & & 4 \\
\hline III & 1 & 3 & & 2 & 1 & 2 & 9 \\
\hline IV & 2 & 1 & & 5 & 4 & 1 & 13 \\
\hline V & 1 & & & & 1 & 2 & 4 \\
\hline VI & 22 & & 2 & 3 & 1 & 39 & 67 \\
\hline Total & 99 & 6 & 6 & 10 & 7 & 44 & 172 \\
\hline
\end{tabular}

Table B.2. Vanek and Postner $(\gamma=0.20)$ methods

\begin{tabular}{||l|c|c|c|c|c|c|c||}
\hline Vanek's Postner 0.20 & I & II & III & IV & V & VI & Total \\
\hline I & 73 & & 2 & & & & 75 \\
\hline II & 2 & 1 & 1 & & & & 4 \\
\hline III & 1 & 3 & 1 & 4 & & & 9 \\
\hline IV & 1 & 1 & 2 & 7 & 3 & & 13 \\
\hline V & 14 & & & & 1 & 2 & 4 \\
\hline VI & 91 & 5 & 6 & 14 & 4 & 52 & 172 \\
\hline Total & & & & & & & 50 \\
\hline
\end{tabular}

Table B.3. Vanek and GOSRPA methods

\begin{tabular}{||l|c|c|c|c|c|c|c||}
\hline \hline Vanek's GOSRPA & I & II & III & IV & V & VI & Total \\
\hline I & 45 & & 1 & & & 29 & 75 \\
\hline II & 2 & 1 & 1 & & & & 4 \\
\hline III & 1 & 3 & 5 & & & & 9 \\
\hline IV & 1 & & 6 & 5 & 1 & & 13 \\
\hline V & 1 & & & & & 3 & 4 \\
\hline VI & 1 & & & 1 & & 65 & 67 \\
\hline Total & 51 & 4 & 13 & 6 & 1 & 97 & 172 \\
\hline \hline
\end{tabular}

Table B.4. Postner $(y=0.10)$ and Postner $(y=0.20)$ methods 
E. Londero Primary-Input Intensities under Alternative Measures ...

\begin{tabular}{||l|c|c|c|c|c|c|c||}
\hline $\begin{array}{c}\text { Postner 0.20 } \\
\text { Postner's 0.10 }\end{array}$ & I & II & III & IV & V & VI & Total \\
\hline I & 86 & 3 & 1 & & & 9 & 99 \\
\hline II & 2 & 2 & 2 & & & & 6 \\
\hline III & 2 & & 3 & 1 & & & 6 \\
\hline IV & & & & 9 & & 1 & 10 \\
\hline V & & & & 2 & 4 & 1 & 7 \\
\hline VI & 1 & & & 2 & & 41 & 44 \\
\hline Total & 91 & 5 & 6 & 14 & 4 & 52 & 172 \\
\hline
\end{tabular}

Table B.5. Postner $(y=0.10)$ and GOSRPA methods

\begin{tabular}{|l|c|c|c|c|c|c|c||}
\hline \hline Postner 0.10 GOSRPA & I & II & II & IV & V & VI & Total \\
\hline I & 49 & 1 & 1 & & & 48 & 99 \\
\hline II & 1 & 3 & 1 & & & 1 & 6 \\
\hline III & 1 & & 2 & 1 & & 2 & 6 \\
\hline IV & & & 5 & 2 & & 3 & 10 \\
\hline V & & & 1 & 3 & 1 & 2 & 7 \\
\hline VI & & & 3 & & & 41 & 44 \\
\hline Total & 51 & 4 & 13 & 6 & 1 & 97 & 172 \\
\hline \hline
\end{tabular}

Table B.6. Postner $(\gamma=0.20)$ and GOSRPA methods

\begin{tabular}{|c|c|c|c|c|c|c|c|}
\hline Postner 0.20 GOSRPA & I & II & III & IV & V & VI & Total \\
\hline I & 48 & & 1 & & & 42 & 91 \\
\hline II & 2 & 3 & & & & & 5 \\
\hline III & 1 & 1 & 4 & & & & 6 \\
\hline IV & & & 8 & 4 & & 2 & 14 \\
\hline $\mathrm{V}$ & & & & 2 & 1 & 1 & 4 \\
\hline VI & & & & & & 52 & 52 \\
\hline Total & 51 & 4 & 13 & 6 & 1 & 97 & 172 \\
\hline
\end{tabular}




\section{References}

Balassa, B. (1979), "A 'Stages' Approach to Comparative Advantage", in I. Adelman (ed.), Economic Growth and Resources. Proceedings of the Fifth World Congress of the International Economic Association, Vol. 4. New York: St. Martin's Press.

Cohen, J. (1960), "A Coefficient of Agreement for Nominal Scales". Educational and Psychological Measurement, Vol. 20, pp. 37-46.

Davis, D. and D. Weinstein (1998), "An Account of Global Factor Trade". NBER Working Paper No. 6785. Cambridge (Mass.): National Bureau of Economic Research.

Deardorff, A. (1984), "Testing Trade Theories and Predicting Trade Flows". In R. Jones and P. Kenen (eds.) Handbook of International Economics, Vol. 1. Amsterdam: NorthHolland.

Engelbrecht, H. (1996), "The Composition of the Human Capital Stock and the Factor Content of Trade: Evidence from West(ern) Germany". Economic Systems Research, Vol. 8, pp. 271-97.

Kendall, M.G. (1970), Rank Correlation Methods, Fourth Edition. London: Griffin.

Lary, H. (1968), Imports of Manufactures form Less Developed Countries. New York: Columbia University Press.

Leamer, E. (1987), "Paths of Development in the Three-Factor, n-Good General Equilibrium Model". Journal of Political Economy, Vol. 95, pp. 961-99.

Leamer, E. and J. Levinsohn (1994), "International Trade Theory: The Evidence". NBER Working Paper No. 4940. Cambridge (Mass.): National Bureau of Economic Research.

Leontief, W. (1953), "Domestic Production and Foreign Trade: The American Capital Position Re-examined". Proceedings of the American Philosophical Society, Vol. 97, pp. 332-49. Reproduced in Leontief (1966).

Leontief, W. (1956), "Factor Proportions and the Structure of American Trade: Further Theoretical and Empirical Analysis", Review of Economics and Statistics, Vol. 38, pp. 386-407. Reproduced in Leontief (1966).

Leontief, W. (1966), Input-Output Economics. New York: Oxford University Press.

Londero, E. (1994), "Preparing Relative Intensity Triangles". Working Papers No. 198. 
Washington, DC: Inter-American Development Bank.

Londero, E. (1998), "Methodology". In E. Londero, S. Teitel et al. (1998).

Londero, E. (1999), "Alternative Measures of Rent Content". International Trade Journal, Vol. 13, pp. 371-84.

Londero, E., J. Remes, and S. Teitel (1998), "Argentina: Natural Resources and Industrial Policy". In Londero, Teitel et al. (1998).

Londero, E., and S. Teitel (1996), "Industrialization and the Factor Content of Latin American Exports of Manufactures". Journal of Development Studies, Vol. 32, pp. 581601.

Londero, E., S. Teitel et al. (1998), Resources, Industrialization and Exports in Latin America. London and New York: Macmillan and St. Martin's.

Maskus, K., C. Sveiskauskas, and A. Webster (1994), "The Composition of the Human Capital Stock and Its Relation to International Trade: Evidence from the US and Britain". Weltwirtschaftliches Archiv, Vol. 130, pp. 51-76.

Moreira, M. and S. Najberg (2000), "Trade Liberalisation in Brazil: Creating or Exporting Jobs?". Journal of Development Studies, Vol. 36, pp. 78-99.

Naya, S. (1967), "Natural Resources, Factor Mix, and Factor Reversal in International Trade". American Economic Review (Proceedings), Vol. 57, pp. 561-70.

Postner, H. (1975), Factor Content of Canadian International Trade: An Input-Output Analysis. Ottawa: Economic Council of Canada.

Ramazami, R. and K. Maskus (1993), "A Test of the Factor Endowments Model of Trade in a Rapidly Industrializing Country: The Case of Korea". Review of Economic and Statistics, Vol. 75, pp. 568-72.

Remes Lenicov, J. (1987), "Revisión, reforma y ampliación de la matriz de insumoproducto de la Secretaría de Planificación. Año 1973" (Revision, Reform and Expansion of the Planning Office Input-Output Table for 1973). Internal working paper.

Washington, DC: Inter-American Development Bank.

Secretaría de Planificación (1986), Cuadro de insumo-producto de los sectores productores de bienes (Input-Output Table for the Good-Producing Sectors). Buenos Aires: Secretaría de Planificación. 
Trefler, D. (1993), "International Factor Price Differences: Leontief was Right!". Journal of Political Economy, Vol. 101, pp.961-987.

United Nations (1971), Indexes to the International Standard Industrial Classification of All Economic Activities. Statistical Papers, Series M, No. 4, Rev. 2, Add. 1. New York: United Nations.

Vanek, J. (1963), The Natural Resource Content of United States Foreign Trade, 18701955. Cambridge (Mass.): MIT Press. 